\title{
Comparison of the effect of ferrous sulfate and ferrous gluconate on prophylaxis of iron deficiency in toddlers 6-24 months old: A Randomized Clinical Trial
}

\author{
vahid falahati ${ }^{1}$, Kazem Ghaffari ${ }^{2}$, ali ghasemi ${ }^{3}$, Aziz Eghbali ${ }^{1}$, Sanaz Khodabakhshi ${ }^{1}$, \\ Amir Almasi-Hashiani ${ }^{1}$, and Bahman sadeghi-sedeh ${ }^{1}$ \\ ${ }^{1}$ Arak University of Medical Sciences \\ ${ }^{2}$ Khomein University of Medical Sciences \\ ${ }^{3}$ Semnan University of Medical Sciences and Health Services
}

January 18, 2021

\begin{abstract}
Background: Iron deficiency is the most common micronutrient deficiency affecting nearly one-third of the population and is the leading cause of anemia worldwide. $\mathrm{n}$ this study, we evaluated the effectiveness of ferrous gluconate and ferrous sulfate supplements to identify the best iron supplement with the most effective and the least side effects in toddlers 6-24 months old. Methods: A randomized, single-blind clinical trial was performed. A total of 120 healthy toddlers aged 6 to 24 months old (two groups of 60) entered the study. Toddlers receiving ferrous sulfate (FS group) and ferrous gluconate (FG group) supplements. Blood indices such as hemoglobin \& ferritin levels were evaluated at baseline and 6 months post- supplementation. Results: The FG group that received ferrous gluconate chelate iron showed approximately $2.4 \mathrm{~g} / \mathrm{dl}$ higher Hb level in comparison to the FS group with ferrous sulfate supplementation 6 months post-supplementation $(12.51 \pm 0.58 \mathrm{~g} / \mathrm{dL}$ vs. $10.10+-0.83, \mathrm{p}=0.045)$. Side effects were significantly more common in the FS group than the FG group (43.3 \% vs. 16.7 \%, P [?] 0.001. Conclusion: The present study shows that educating mothers to feed toddlers with breast milk and iron supplements, including ferrous sulfate and ferrous gluconate, can be helpful in the prophylaxis of iron deficiency. Our results show that ferrous gluconate can be used in cases where ferrous sulfate causes unacceptable side effects.
\end{abstract}

Title page

Original article

Comparison of the effect of ferrous sulfate and ferrous gluconate on prophylaxis of iron deficiency in toddlers 6-24 months old: a Randomized Clinical Trial

Running title: FERROUS SULFATE AND FERROUS GLUCONATE SUPLEMENTS

Vahid Falahati MD ${ }^{1}$, Kazem Ghaffari $\mathrm{MSC}^{2}$, Ali Ghasemi Ph.D ${ }^{3 *}$, Aziz Eghbali MD ${ }^{4}$, Sanaz Khodabakhshi $\mathrm{MD}^{5}$, Amir Almasi-Hashiani Ph.D ${ }^{6}$, Bahman sadeghi-sedeh $\mathrm{MD}^{7}$

1. Assistance Professor, Clinical Research Development Center of Amirkabir Hospital, Arak University of Medical Sciences, Arak, Iran. E-mail: vahidfalahati@outlook.com

2. Instructor, Department of Base and Laboratory Sciences, Khomein University of Medical Sciences, Khomein, Iran. E-mail: khomeinums.ac.ir

3. Assistance Professor, Department of Biochemistry and Hematology, Faculty of Medicine, Semnan University of Medical Sciences, Semnan, Iran. E-mail: a.qasemi2012@yahoo.com 
4. Associate Professor, Clinical Research Development Center of Aliasghar Hospital, Iran University of Medical Sciences, Tehran, Iran. E-mail: Dr.eghbali@arakmu.ac.ir. Orchid: 0000-0002-5118-0094

5. Medical student, Clinical Research Development Center of Amirkabir Hospital, Arak University of Medical Sciences, Arak, Iran. E-mail: ghaffari_kazem@yahoo.com

6. Assistance Professor, Department of Epidemiology, Arak University of Medical Sciences, Arak, Iran. E-mail: razi.tums.ac.ir

7. Associate Professor, Department of Social Medicine, Arak University of Medical Sciences, Arak, Iran. E-mail: arakmu.ac.ir

*Corresponding author: Ali Ghasemi

Assistance Professor, Department of Biochemistry and Hematology, Faculty of Medicine Semnan University of Medical Sciences, Semnan, Iran.

E-mail: a.qasemi2012@yahoo.com

Tel: 09127853696

Orchid ID: 0000-0002-4996-7656

\section{Financial disclosure:}

None declared

Word Count for Abstract: 221

Word Count for Main Text: 1868

The number of Tables: 5

Keywords: Ferrous sulfate, Ferrous gluconate, Iron deficiency

Abbreviations

\begin{tabular}{ll}
\hline Abbreviations & Full term \\
FS & Ferrous sulfate \\
FG & Ferrous gluconate \\
IDA & Iron deficiency anemic \\
WHO & World Health Organization \\
Hb & Hemoglobin \\
Hct & Hematocrit \\
RBCs & Red blood cells \\
MCV & Mean cell volume \\
MCH & Mean corpuscular hemoglobin \\
MCHC & Mean corpuscular hemoglobin concentration \\
RDW & Red cell distribution width \\
\hline
\end{tabular}

\section{Hosted file}

Iron supplements.pdf available at https://authorea.com/users/390280/articles/504660comparison-of-the-effect-of-ferrous-sulfate-and-ferrous-gluconate-on-prophylaxis-ofiron-deficiency-in-toddlers-6-24-months-old-a-randomized-clinical-trial

\section{Hosted file}

Tables.pdf available at https://authorea.com/users/390280/articles/504660-comparison-of-theeffect-of-ferrous-sulfate-and-ferrous-gluconate-on-prophylaxis-of-iron-deficiency-intoddlers-6-24-months-old-a-randomized-clinical-trial 